\title{
Association of Older Sister's HPV Vaccination Status on HPV Vaccine Receipt by Adolescents
}

\author{
Sarah J. Clark, MPH, Anne E. Cowan, MPH, Stephanie L. Filipp, MPH, \\ Allison M. Fisher, MPH, and Shannon Stokley, MPH
}

Objective: Efforts to increase human papillomavirus (HPV) vaccine coverage rates in adolescents include finding ways to improve discussions between clinicians and parents. One potentially important piece of information for these discussions is the HPV vaccination status of older siblings.

Methods: A nationally representative online panel was used to conduct a cross-sectional survey of parents of children aged 9 to 17 years in October 2012.

Results: Overall, 768 adolescents $(35 \%)$ had $\geq 1$ older sister aged 10 to 26 years. Male and female adolescents with an older sister who had received no HPV vaccine doses demonstrated higher rates of having no doses themselves, compared with those who had no older sister or those who had an older sister who had received $\geq 1 \mathrm{HPV}$ vaccine dose.

Conclusions: Discussing the HPV vaccination status of older sisters may be a useful strategy for providers to differentiate HPV vaccine messages to parents of unvaccinated younger siblings. ( $\mathrm{J}$ Am Board Fam Med 2015;28:816-818.)

Keywords: Adolescence, HPV Vaccines, Immunization

Findings from a nationally representative online survey of parents show that human papillomavirus (HPV) vaccination status of older sisters is associated with HPV vaccine receipt among adolescents. This knowledge can help clinicians tailor their discussions with parents about the HPV vaccine.

Routine vaccination of adolescents against HPV has been recommended for females since 2006 and males since 2011. ${ }^{1,2} \mathrm{HPV}$ vaccination coverage lags behind coverage for other adolescent vaccines; for

This article was externally peer reviewed.

Submitted 15 May 2015; revised 22 July 2015; accepted 29 July 2015.

From the Child Health Evaluation and Research Unit, University of Michigan, Ann Arbor (SJC, AEC, SLF); and the Immunization Services Division, National Center for Immunization and Respiratory Diseases, Centers for Disease Control and Prevention, Atlanta, GA (AMF, SS).

Funding: This work is a product of a prevention research center and was supported by the Centers for Disease Control and Prevention through Cooperative Agreement no. 5-U48-DP-001901.

Conflict of interest: none declared.

Disclaimer: The findings and conclusions are those of the authors and do not necessarily represent the official position of the Centers for Disease Control and Prevention.

Corresponding author: Sarah J. Clark, MPH, Child Health Evaluation and Research Unit, University of Michigan, 300 North Ingalls, 6E06, Ann Arbor, MI 48109-5456 (E-mail: saclark@med.umich.edu). example, in 2012, vaccination rates among adolescents aged 13 to 17 years were $85 \%$ for the tetanus, diphtheria, and pertussis vaccine, and $74 \%$ for the meningococcal vaccine, whereas for the HPV vaccine the rates for $\geq 1$ dose were $54 \%$ for females and $21 \%$ for males. ${ }^{3}$ Common reasons for not receiving the HPV vaccine include parental lack of knowledge about the vaccine, belief that the vaccination will promote sexual activity, cost, and lack of a provider's recommendation. ${ }^{4}$ Strategies to increase HPV vaccine coverage rates include improving communication between clinicians and families. ${ }^{5}$ One issue that could influence this discussion is parental experience with HPV vaccination of older siblings. The objective of this study was to explore the association between the HPV vaccination status of US adolescents aged 9 to 17 years and receipt of the HPV vaccine by their older sisters.

\section{Methods}

We conducted a nationally representative, crosssectional survey of parents of children aged 9 to 17 years using GfK's online KnowledgePanel. ${ }^{6}$ KnowledgePanel is a probability-based panel that is representative of the US population in terms of 
respondent sex, age, race/ethnicity, education, and Census region. Panel members were selected using address-based probability sampling. Households are provided with Internet access and hardware, if needed.

This 22-question survey was fielded in October 2012 to 3177 panel members identified from GfK profile data as being a parent of $\geq 1$ child aged 9 to 17 years. The survey was administered in English and Spanish, and had a completion rate of $57 \%$ (1799 of 3177); 1653 of the 1799 survey respondents reported being a parent of $\geq 1$ child aged 9 to 17 years (92\% eligibility rate).

Respondents reported the age and sex of their children 9 to 17 years old and the number of HPV vaccine doses those children received $(0,1,2$, or 3 doses); and the age and sex of their children 18 to 26 years old and HPV vaccine receipt (any or no doses) among those children. We classified adolescents aged 9 to 17 years into 3 groups based on whether they had $\geq 1$ older sister aged 10 to 26 years who had received no HPV vaccine doses, $\geq 1$ older sister who had received any HPV vaccine doses, or no older sister aged 10 to 26 years.

GfK provided de-identified data, and Censusbased post-stratification weights were used to match the US population distribution on respondent sex, age, race/ethnicity, education, and Census region. The study team generated frequency distributions, as well as bivariate analyses of adolescent HPV vaccination status by older sister(s)' vaccination status; these analyses were performed by age/ sex grouping (females 9 to 12 and 13 to 17 years, males 9 to 12 and 13 to 17 years). Unweighted numbers and weighted proportions are presented. The study was approved by the University of Michigan Medical School Institutional Review Board.

\section{Results}

The 1653 respondents reported complete data on age, sex, and number of HPV vaccine doses for 2511 adolescents aged 9 to 17 years. Receipt of $\geq 1$ dose of the HPV vaccine was $48 \%$ among females 13 to 17 years, $21 \%$ among females 9 to 12 years, $26 \%$ among males 13 to 17 years, and 19\% among males 9 to 12 years.

Overall, 768 adolescents (35\%) had $\geq 1$ older sister aged 10 to 26 years. Across sex and age groups, adolescents with an older sister who had received no HPV vaccine doses demonstrated
Table 1. Human Papillomavirus Vaccine (HPV) Receipt Among Adolescents By Sex/Age Group and Human Papillomavirus Vaccine Vaccination Status of Older Sisters

\begin{tabular}{|c|c|c|c|c|}
\hline & \multirow{2}{*}{$\begin{array}{l}\text { Adolescents } \\
\text { (unweighted n) }\end{array}$} & \multicolumn{3}{|c|}{$\begin{array}{c}\text { HPV Doses } \\
\text { Received } \\
\text { (weighted } \\
\text { n, \%) }\end{array}$} \\
\hline & & 0 & 1 or 2 & 3 \\
\hline \multicolumn{5}{|l|}{ Females aged $9-12$ years* } \\
\hline No older sister & 345 & 79 & 16 & 5 \\
\hline $\begin{array}{l}\text { Older sister(s), no HPV } \\
\text { doses }\end{array}$ & 104 & 93 & 7 & 0 \\
\hline $\begin{array}{l}\text { Older sister(s), any HPV } \\
\text { doses }\end{array}$ & 93 & 54 & 29 & 17 \\
\hline \multicolumn{5}{|l|}{$\begin{array}{l}\text { Females aged } \\
\text { years }^{* \dagger}\end{array}$} \\
\hline No older sister & 467 & 52 & 21 & 27 \\
\hline $\begin{array}{l}\text { Older sister(s), no HPV } \\
\text { doses }\end{array}$ & 121 & 81 & 12 & 7 \\
\hline $\begin{array}{l}\text { Older sister(s), any HPV } \\
\text { doses }\end{array}$ & 118 & 21 & 27 & 52 \\
\hline \multicolumn{5}{|l|}{ Males aged 9-12 years* } \\
\hline No older sister & 377 & 76 & 20 & 4 \\
\hline $\begin{array}{l}\text { Older sister(s), no HPV } \\
\text { doses }\end{array}$ & 115 & 98 & 2 & 0 \\
\hline $\begin{array}{l}\text { Older sister(s), any HPV } \\
\text { doses }\end{array}$ & 108 & 75 & 18 & 7 \\
\hline \multicolumn{5}{|l|}{ Males aged $13-17$ years ${ }^{* \dagger}$} \\
\hline No older sister & 454 & 74 & 20 & 6 \\
\hline $\begin{array}{l}\text { Older sister(s), no HPV } \\
\text { doses }\end{array}$ & 93 & 91 & 5 & 4 \\
\hline $\begin{array}{l}\text { Older sister(s), any HPV } \\
\text { doses }\end{array}$ & 116 & 59 & 25 & 16 \\
\hline
\end{tabular}

${ }^{*} P<.001$, comparison of 0 vs $\geq 1$ dose.

${ }^{\dagger} P<.001$, comparison of 0 vs 1 or 2 vs 3 doses.

higher rates of having no HPV vaccine doses themselves, compared with either adolescents with no older sister or those with an older sister who had received $\geq 1 \mathrm{HPV}$ vaccine dose (Table 1 ).

\section{Discussion}

We found that HPV vaccine receipt by an older sister (up to age 26 years) is correlated with HPV vaccine receipt among younger sisters. By contrast, having an older sister who received no HPV vaccine doses was strongly associated with receipt of no doses among younger sisters and brothers. Asking about the HPV vaccination status of older siblings may help clinicians tailor their discussions around the HPV vaccine. For example, identifying that an older daughter did not receive the HPV 
vaccine could prompt a discussion of the reasons why she was not vaccinated, which could in turn provide an opportunity to convey current data on safety and effectiveness, ${ }^{5}$ discuss insurance coverage for vaccination, and emphasize the vaccine's protection against different types of cancer. ${ }^{7}$ Counseling parents about a younger sibling's HPV vaccination also may prompt a discussion about catch-up vaccination of an unvaccinated older sister or brother.

Although the study is limited by a lack of clinical verification of $\mathrm{HPV}$ vaccine receipt, parent report has been shown to be a reasonable approximation of provider-reported rates. ${ }^{8}$ The rates for completion of $\geq 1$ dose of HPV vaccine from this study vary slightly from national, provider-verified rates for the same year, which may be the result of substantially lower participation rates for the national provider-verified data. ${ }^{3}$

\section{Conclusion}

Asking about the HPV vaccination status of older sisters may be a useful strategy for providers to differentiate HPV vaccine messages.

\section{References}

1. Markowitz LE, Dunne EF, Saraiya M, Lawson HW, Chesson H, Unger ER; Centers for Disease Control and Prevention (CDC); Advisory Committee on Immunization Practices (ACIP). Quadrivalent human papillomavirus vaccine: recommendations of the Advisory Committee on Immunization Practices (ACIP). MMWR Recomm Rep 2007;56(RR-2):1-24.
2. Centers for Disease Control and Prevention. Recommendations on the use of quadrivalent human papillomavirus vaccine in males-Advisory Committee on Immunization Practices (ACIP), 2011. MMWR Morb Mortal Wkly Rep 2011;60:1705-8.

3. Centers for Disease Control and Prevention. National and state vaccination coverage among adolescents aged 13-17 years-United States, 2012. MMWR Morb Mortal Wkly Rep 2013;62:685-93.

4. Holman DM, Benard V, Roland KB, Watson M, Liddon N, Stokley S. Barriers to human papillomavirus vaccination among US adolescents: a systematic review of the literature. JAMA Pediatr 2014;168: $76-82$.

5. Stokley S, Jeyarajah J, Yankey D, et al; Immunization Services Division, National Center for Immunization and Respiratory Diseases, CDC; Centers for Disease Control and Prevention (CDC). Human papillomavirus vaccination coverage among adolescent, 2007-2013, and postlicensure vaccine safety monitoring, 2006-014-United States. MMWR Morb Mortal Wkly Rep 2013;63:620-4.

6. KnowledgePanel Design Summary. Palo Alto (CA): GfK; 2013. Available from: http://www.knowledgenetworks.com/knpanel/docs/knowledgepanel(R)design-summary-description.pdf. Accessed September 30, 2014.

7. Grimes RM, Benjamins LJ, Williams KL. Counseling about the HPV vaccine: desexualize, educate, and advocate. J Pediatr Adolesc Gynecol 2013;26:243-8.

8. Ojha RP, Tota JE, Offutt-Powell TN, Klosky JL, Ashokkumar R, Gurney, JG. The accuracy of human papillomavirus vaccination status based on adult proxy recall or household immunization records for adolescent females in the United States: results from the National Immunization Survey-Teen. Ann Epidemiol 2013;23:281-5. 